\title{
STRATEGIC COMMITTEE INVOLVEMENT
}

\author{
A GUIDE FOR FACULTY DEVELOPERS
}

Phyllis Blumberg, University of the Sciences in Philadelphia

Faculty developers should seek purposeful involvement in committee service because committees are essential to the functioning of higher education institutions. The unique expertise and perspectives that faculty developers bring to the table help committees execute their tasks and benefit faculty development efforts. Given the number of possible institutional committees and limitations on time, developers should decide carefully about their service. Offered here is a framework for making strategic decisions about committee membership on five criteria: committee characteristics, individual's impact on the committee, personal characteristics, conditions that should discourage service, and pitfalls to consider before deciding to serve.

Committees and task forces represent the sharing of governance between administrators and faculty (Marshall, 1999). They can alter the culture and policies of an institution, thereby influencing teaching and learning, institutional practices, and educational programs (Schroeder, 2006). As they consider important initiatives regarding student assessment, curriculum revision, and course and faculty evaluation, they can act as change agents themselves and can attract people interested in change. Because committees and task forces (henceforth, I use "committee" to mean both) play such an essential role in the functioning of institutions of higher education, faculty developers should seek purposeful involvement in them (Gillespie \& Zinsmeister, 2004; Schroeder, 2006) and view committee service in the context of their normal consultative and educational roles with faculty. 
Yet many developers do not embrace committee service. They may believe that committee work takes time away from other pressing responsibilities. Indeed, such service is time-consuming, which is why Diamond (1995) advises faculty to limit it to less than 20 percent of their time. However, his guideline may not be appropriate for faculty developers, who have different responsibilities. Manuals on faculty development (for example, Gillespie, Hilsen, \& Wadsworth, 2002) are silent on both the importance of committee service and the proportion of time it is worth. In addition, few sessions at the annual POD Network conferences address the subject of committee involvement for faculty developers; nor do orientations for new faculty developers. Perhaps the profession regards committee work as ancillary because of its traditional service and support roles emphasizing one-on-one consultation with faculty and small-group workshops (Lieberman \& Guskin, 2003).

However, POD Network leaders are now fostering another model of faculty development with an institutional focus (Baron, 2006; Chism, 1998; Lieberman \& Guskin, 2003; Schroeder, in press). Chism (1998) calls this a paradigm shift in faculty development, from reactive.individual consultation and training to proactive organizational development. With this new paradigm, faculty developers need easy access to governance bodies, decision makers, and the faculty at large, which committee participation affords (Chism, 1998). Lieberman and Guskin (2003) contend that developers now need to be seen as change agents who work to transform their institutions to support not only faculty but administrators and faculty leaders as well. When engaged in institutionwide activities, they work collaboratively with a variety of campus units and can serve as catalysts and active participants of institutional change (Baron, 2006).

To determine the extent and channels of the institutional influence of faculty developers, Schroeder (in press) surveyed 149 center directors across all types of institutions. She classified their responses about their centers on a continuum from marginalized to acting as leaders within the central functions of their institutions. She found that centers she defined as marginalized focused their attention on individual faculty, in sharp contrast to those centers that she classified as key leaders. More than 61 percent of the latter had an institutional focus, while only 12 percent of the marginalized centers did. Virtually all of the centers in leadership roles were involved in committee work, often with heavy responsibilities, which was one of thirty-six factors that enhanced their institutional impact. Committee involvement, then, is a key component of the new proactive, leadership model of the profession. 
Faculty developers can forge a reciprocal exchange of benefits between the institutional committees on which they serve and their own centers. For their own benefit, they can network and establish trust and rapport with a range of faculty and administrators whom they might not otherwise meet through their center work. They also gain a sense of how faculty members and administrators think about issues, adding other perspectives to those acquired through center-based contacts. For the institution's benefit, they can offer their unique expertise and knowledge to the decision-making process. In fact, when committees are charged with developing new initiatives or directions, the presence and leadership of a faculty developer may have a greater influence on the outcomes than all of the workshops and learning communities that may grow out of these new initiatives (Schroeder, 2006).

\section{Roles on Committees}

How an individual comes to serve on a given committee has implications for faculty developers. If he or she is elected, this usually signifies a vote of faculty confidence. If administrators or faculty leadership ask a faculty developer to serve on a committee as a regular, ex-officio, or staff member, it is usually because that individual has special, needed expertise. In some cases, faculty developers automatically serve on certain committees because of their expertise, knowledge, perspective, or job responsibilities. Their supervisor may request or recommend membership on a specific committee for the same reason.

However, faculty developers can actively seek committee membership by volunteering, self-nominating, or talking to decision makers about the value they can bring to the committee (expertise, knowledge, perspective) or their interest in learning more about its work. Even if faculty developers do not hold faculty rank and may not be eligible for academic committees, they can still participate on the committee in a number of ways: by seeking out the chairperson and presenting background or literature on a topic, by asking to sit in at meetings or present relevant information, and by attending open meetings, especially those where the agenda pertains to what they do.

Despite the benefits that can mutually accrue, faculty developers should make wise committee-service choices. Most focus on improving the quality of instruction (Diamond, 2002), which involves improving instructor teaching knowledge and behavior, courses and curriculum, and organizational processes related to the teaching mission. Therefore, faculty developers should target committees congruent with these purposes. For example, committees that plan an outside speaker series or determine 
policies related to workload or class size can help instructors improve how they teach. Curriculum committees address ways to improve instruction, such as innovative types of courses, active learning strategies, and more valid assessment methods. Strategic planning and program development shape organizational processes. Student and program assessment committees are also linked to the faculty developer's domains.

\section{Framework to Guide Decisions About Serving on Specific Committees}

Given the number of possible committees and limitations on time, faculty developers may find a framework for seeking or selecting committee involvement helpful. The one I propose here rates the value of their involvement on five criteria: committee characteristics, potential impact of the faculty developer on the committee, personal characteristics, conditions that should deter faculty developers from serving, and pitfalls to consider before deciding to serve, as shown in the table (4.1) in the appendix. Alone or in consultation with others, faculty developers can apply this framework to any potential committee assignment, including whether to continue or end membership. In the next few pages, I explain each section of the framework and furnish examples of applying the framework to specific committee service options.

I used a modified critical incidents method to assign positive, negative, and neutral points as a soft indicator of whether to serve on a particular committee; therefore, the numbers given are value judgments. The number of total positive point considerations for serving on a committee is about the same as the total negative point considerations against serving. When a scale is given, the individual completing the framework should assess the appropriate rating for the committee being considered. Then, after completing this framework, he or she should add up the positive and the negative points, count the number of points given as neutral, and examine the balance among these categories. The greater the total positive points, the potentially more valuable this committee service; the greater the total negative points, the potentially less value or more hazardous the service, or the less visible one's role should be.

Rather than recommending cutoff scores for deciding about committee work, I leave the individual to decide on the basis of the institutional culture. Sometimes a particular committee may have a low positive score, but one may be required to serve on it. In this case, one may want to limit visibility or try to change the role to that of an advisor, resource person, or nonvoting member. 


\section{Committee Characteristics}

Committee characteristics (Section A in Table 4.1) include its mission and perceived institutional prestige. For instance, committees that prepare materials for accreditation or steering committees for accreditation review relate to essential faculty development functions and carry considerable prestige and visibility, so they are good candidates for the faculty developer's service (Gillespie, in press). In contrast are committees that determine scholarships, graduation awards, athletic conferences, and other matter unconnected to faculty development.

\section{Potential Impact of the Faculty Developer on the Committee}

Potential impact (Section B in Table 4.1) encompasses a dozen ways in which faculty developers can add value (sometimes uniquely so) to a committee. For example, unlike faculty members, faculty developers often have the expertise and funding to invite outside speakers to campus, promote dialogues on topics, and support faculty travel to relevant meetings. They might consider serving on a facilities or teaching environment committee because it has the power to improve the quality of teaching and learning (Gillespie, in press). Marilla Svinicki of the University of Texas at Austin (personal communication, May 4, 2003) recounted her success promoting active learning in large classrooms when she convinced her university to replace the theater-style bolted-down seating with movable chairs. Facilities committees often address this type of topic, and faculty developers can research how other institutions have designed learning spaces and bring relevant articles or websites into committee discussions on classroom design. They can also promote dialogue on designs for learning among faculty and administrators, describe new approaches to learning spaces, and help people to think creatively about merging laboratories and classrooms into studio science classrooms, for example (Beichner \& Saul, 2003). Faculty developers can meet with the chair or influential members one-on-one outside of formal meetings to teach them about flexible learning environments. They can also encourage others to question the status quo. Finally, they can help translate architects' ideas to committee members and vice versa.

Whether or not faculty developers use the framework for committee work decisions, they can enhance their overall impact on a committee by performing as many of the roles listed in Section B, Table 4.1 as appropriate. These roles furnish opportunities to display proactive leadership and educate committee members and the institution at large. Some of them also have an impact on the committee's ability to effect change and 
promote more effective and efficient institutional operations-for example, by providing process consultation or proposing alternative ways to run the committee if an impasse occurs.

\section{Personal Characteristics}

Personal characteristics (Section C, Table 4.1) refer to what faculty developers bring to a committee, including the role they might play on the committee, their job-related expertise, and other areas of expertise arising from their background or strengths. Because of their position, they have tremendous knowledge about pedagogy, instructional technology, curriculum development, and assessment of student learning at the course and program level. They may also be skilled in group facilitation and can apply this to the committee process. Faculty developers are familiar with current controversies and trends in higher education in general and in specific areas such as faculty roles, responsibilities, and academic governance. They typically can describe the local context and the institutional culture, its history, and its unspoken norms and taboos. They often have well-honed skills in oral and written communication, quantitative and qualitative research, and development of assessment tools that can help committees charged with data gathering and producing a report.

Individual faculty developers can bring unique skills to committees because of their disciplinary background and special areas of expertise and interest, and they may volunteer to serve or run for election on the basis of these skills. For example, being an educational psychologist with a strong background in learning and curriculum development, I choose to serve on committees responsible for developing new educational programs and curricula or conducting the self-study needed for professional program accreditation. While reviewing course or program proposals in committee deliberations, I often highlight the importance of active learning, student engagement, and learning-centered teaching. An instructional designer with distance learning experience may serve more effectively on a technology committee.

\section{Conditions That Should Deter Faculty Developers from Serving}

Two overriding conditions should deter faculty developers from serving on a committee (Section D, Table 4.1). The first is a conflict of interest between the faculty development mission and the committee charge. For example, faculty developers should not serve on promotion and tenure committees. They must avoid the appearance of serving as judge, lest they 
lose the trust of faculty. The second condition arises when faculty perceive a committee as undermining their best interests. For example, if the administration wants to change the terms under which faculty serve the university, and faculty see the change as an antifaculty move, then faculty developers should not be associated with any committee promoting the change. Because a committee either does or doesn't subvert faculty interests, I did not assign a range to this item.

\section{Conditions That Should Cause Faculty Developers to Reconsider}

Section E in Table 4.1 lists conditions that should cause faculty developers to reconsider serving but that are not as severe as the conditions that should deter service. Individuals who are new to the institution or to faculty development might consult with others about the potential risks or pitfalls of specific committees.

People can make enemies by serving on controversial committees or by taking an unpopular stand. Unfortunately, some faculty members and administrators do not confine disagreements to the topic at hand and may extend them to estimate the individual's total value or worth to the institution. Thus, taking a controversial stand could damage one's credibility and even that of an entire faculty development effort. For example, while serving on a task force to revise the general education program, I recommended a major reform that required assessing many cross-disciplinary outcomes, such as information literacy and the ability to work in teams. Many faculty thought the program was unworkable, and some believed I was trying to marginalize their currently required courses in the proposed curriculum. Chairs and faculty alike criticized me (and some of them still hold it against me). I have heard that they trust my center less because of my stand.

Another condition that justifies reconsideration of service is how timeconsuming a committee may be. Numerous meetings with little in the way of concrete progress can be frustrating, whether due to poor leadership, too sweeping a charge, or too ill-defined a task. Some faculty developers might be able to advise the chair in private on how to make the committee more productive, but otherwise they should consider becoming less active. In any case, faculty developers should balance the benefits against the time commitment. A time-consuming committee with a potentially major impact may be a good time investment.

If any pitfall or condition applies to one of their committee memberships, faculty developers should reassess their serving or look into changing their role. For instance, they might replace member status on a 
controversial committee with a staff position. Certainly they should avoid chairing such a committee.

\section{Applying the Framework to an Example}

In Table 4.1, I use the framework to illustrate how I decided to continue serving on a curriculum committee. I chose this committee because its charges-reviewing and deciding on new courses and educational programs and conducting periodic program reviews to ensure that all requirements are met-are consistent with many faculty development missions. In my institution, the universitywide curriculum committee oversees the general education curriculum and universitywide graduation requirements, and it reviews new educational programs. As expected, I have contributed my knowledge of curriculum development, pedagogy, and assessment to the committee's deliberations.

The third column in the table describes my rationale for my ratings, which appear in column four. The totals for my decisions about this committee indicate many more positives (sum of forty-three points) than negatives (sum of minus ten points), plus five neutral items. My membership could have a greater potential impact if this committee had more of a policy-making mandate than an approval function, or if it were more involved with developing new programs or a new general education curriculum. However, given the potential negative impacts of the committee, it may be wisest for faculty developers to serve on it, but not chair it. One year, I did serve as chair and found that this position gave me (and therefore the Teaching and Learning Center) too much visibility when courses were not approved or had to be revised repeatedly.

\section{Conclusion}

Faculty developers have good reason to seek institutional committee involvement. It enhances the credibility and visibility of their own efforts and broadens their influence among faculty and administrators. By contributing their unique expertise, knowledge, and perspectives to the discussion, they improve the functioning of the committees they join. Acting as change agents, they can influence the committee's outcomes and thus the entire institution.

As faculty developers expand their focus from individual faculty to the institution, serving on or helping to lead university- or collegewide committees and task forces becomes a more essential facet of their work. With this institutional orientation, they must ensure they are represented on key 
committees that affect the education of students. Through strategic committee involvement, faculty developers can transition from playing reactive, supportive roles to assuming proactive, leadership responsibilities. In fact, their being proactive on key committees may have an impact on teaching and learning at the institution more than can the one-on-one consultations and small-group workshops that they normally offer.

Because institutions of higher education have so many committees, faculty developers must select their committee participation with care. The framework introduced here can help them make strategic decisions about whether or not to serve, and in what role to serve on a given committee. Further, the framework is useful for teaching center staff as well. In fact, staff deliberations about committee memberships can lead to important related discussions about the center's direction, mission, and vision. 


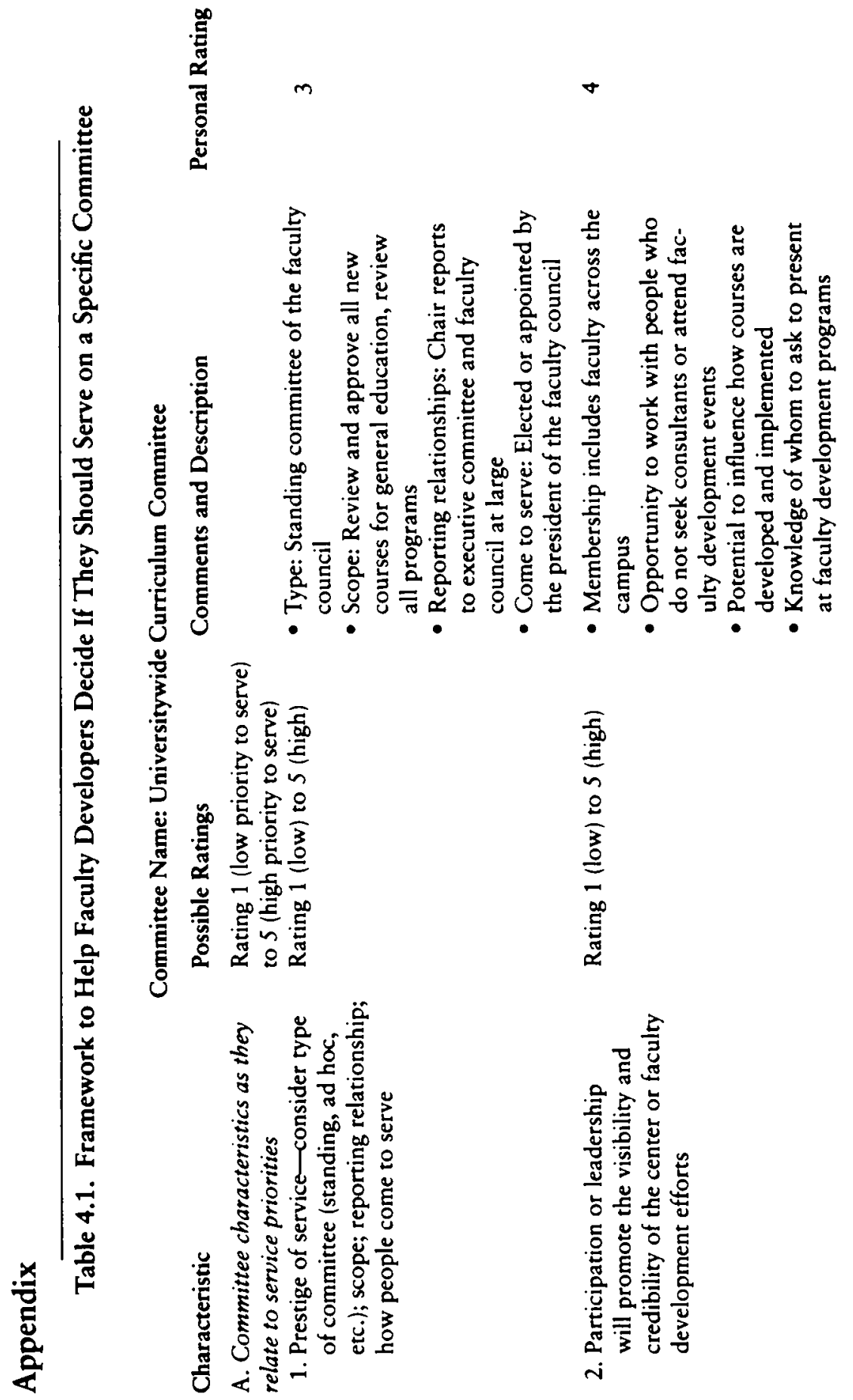










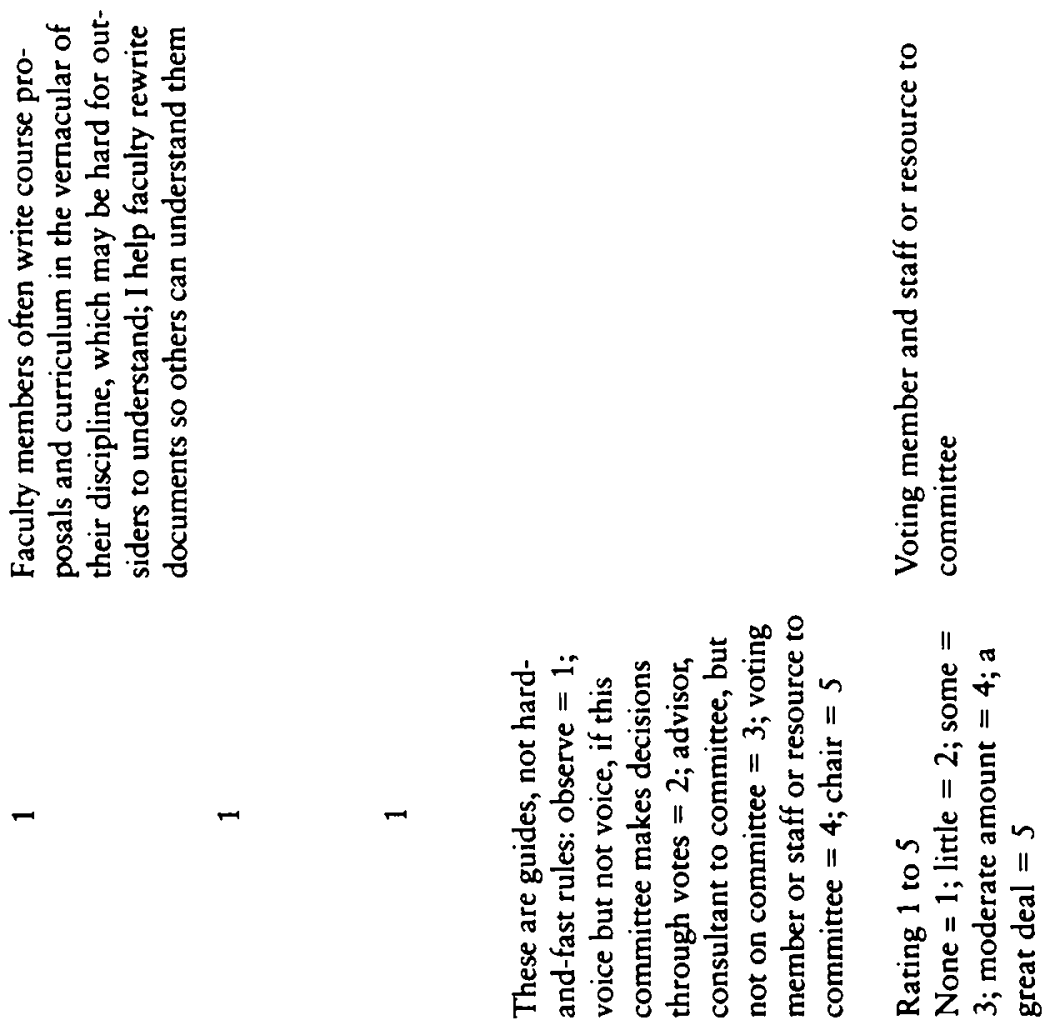

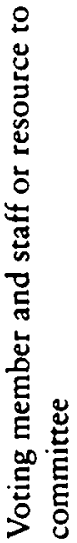

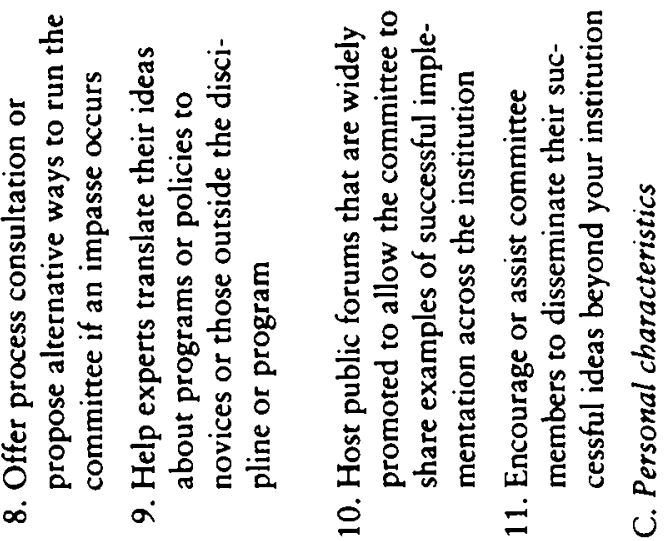




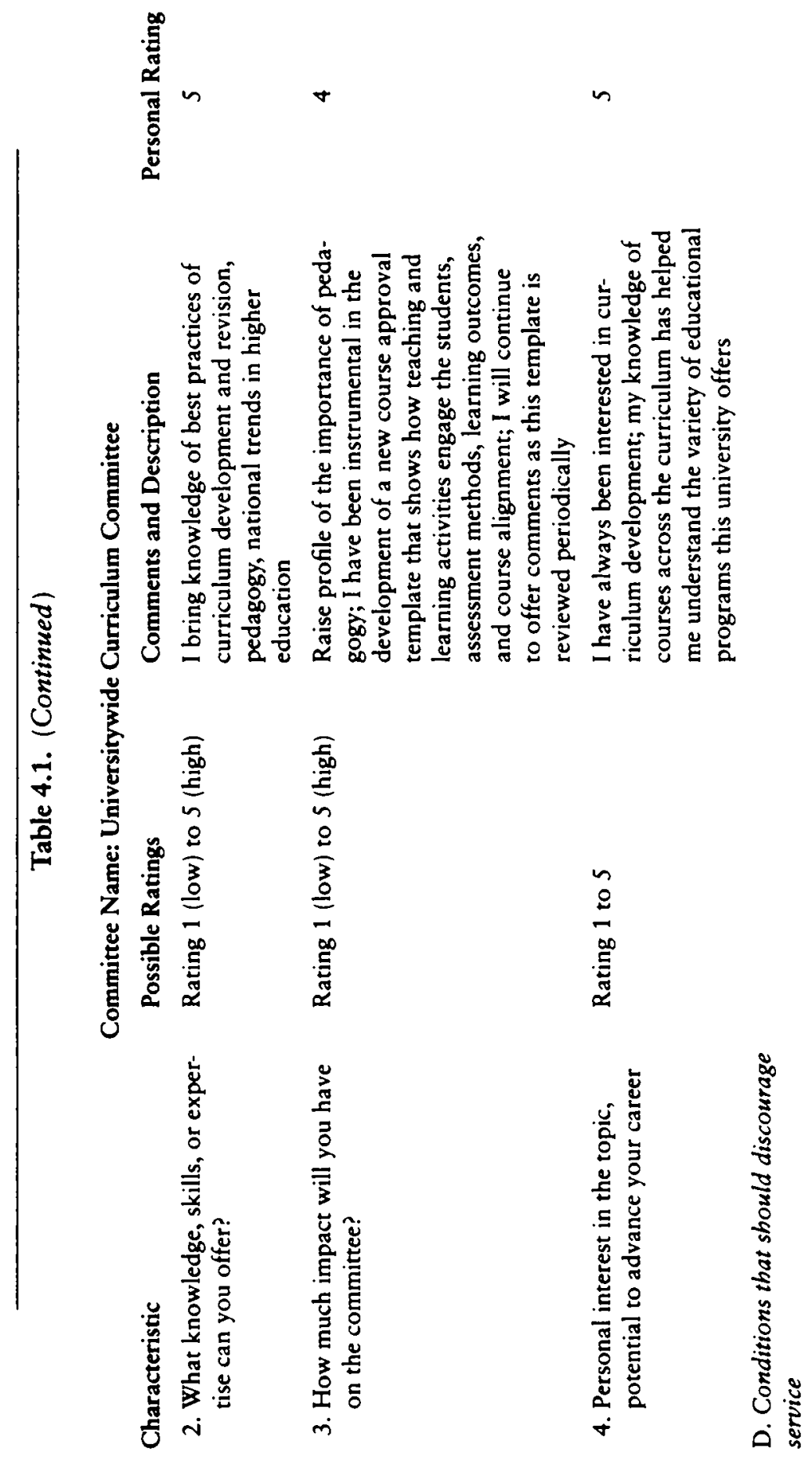


00

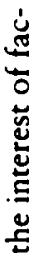

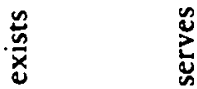

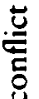

2

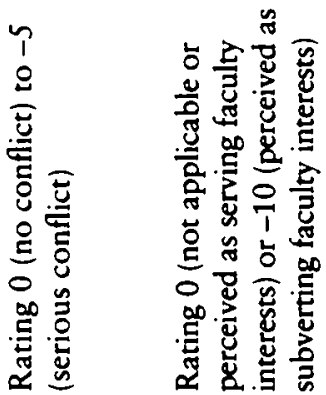

$\uparrow$

$n N$
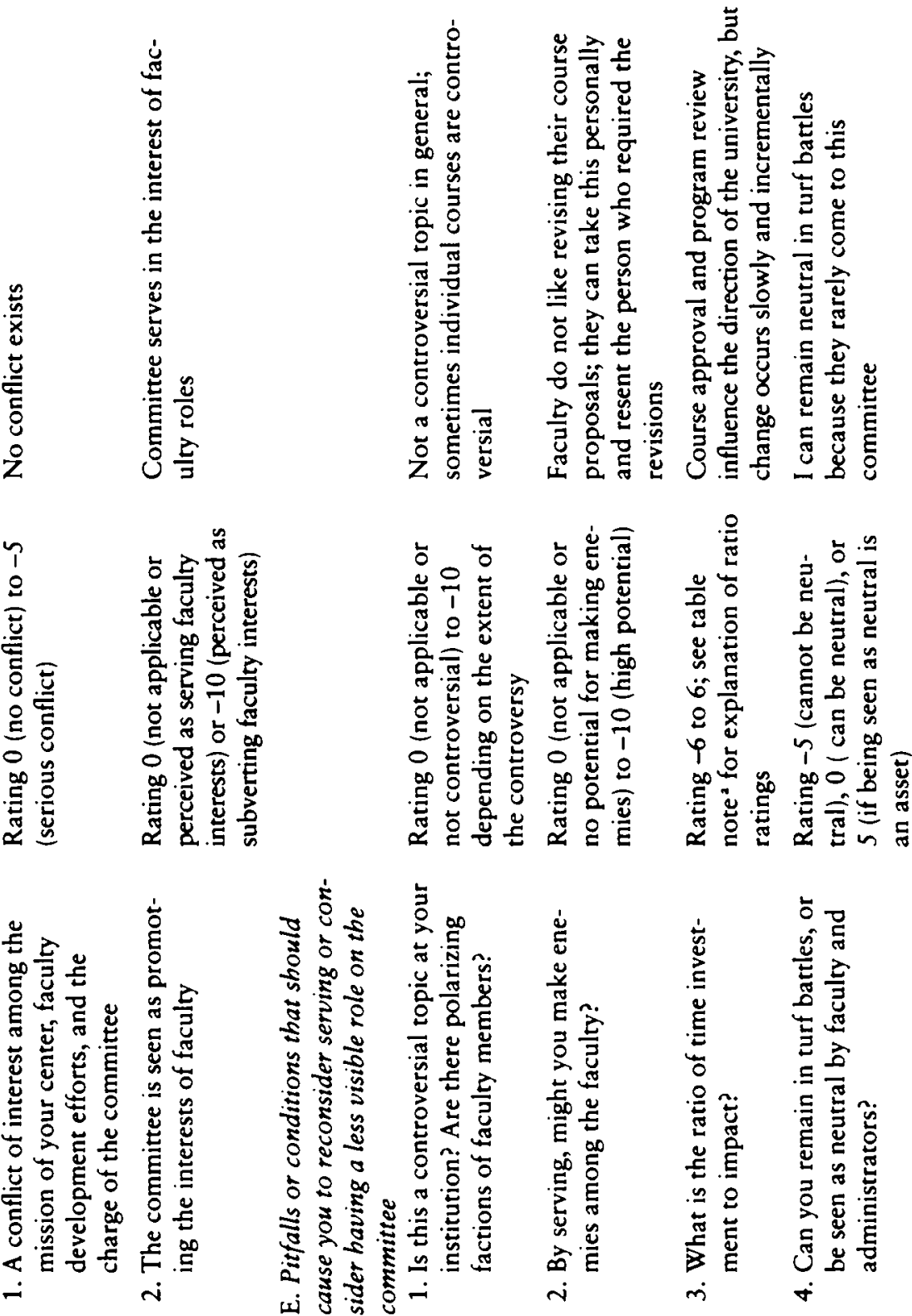


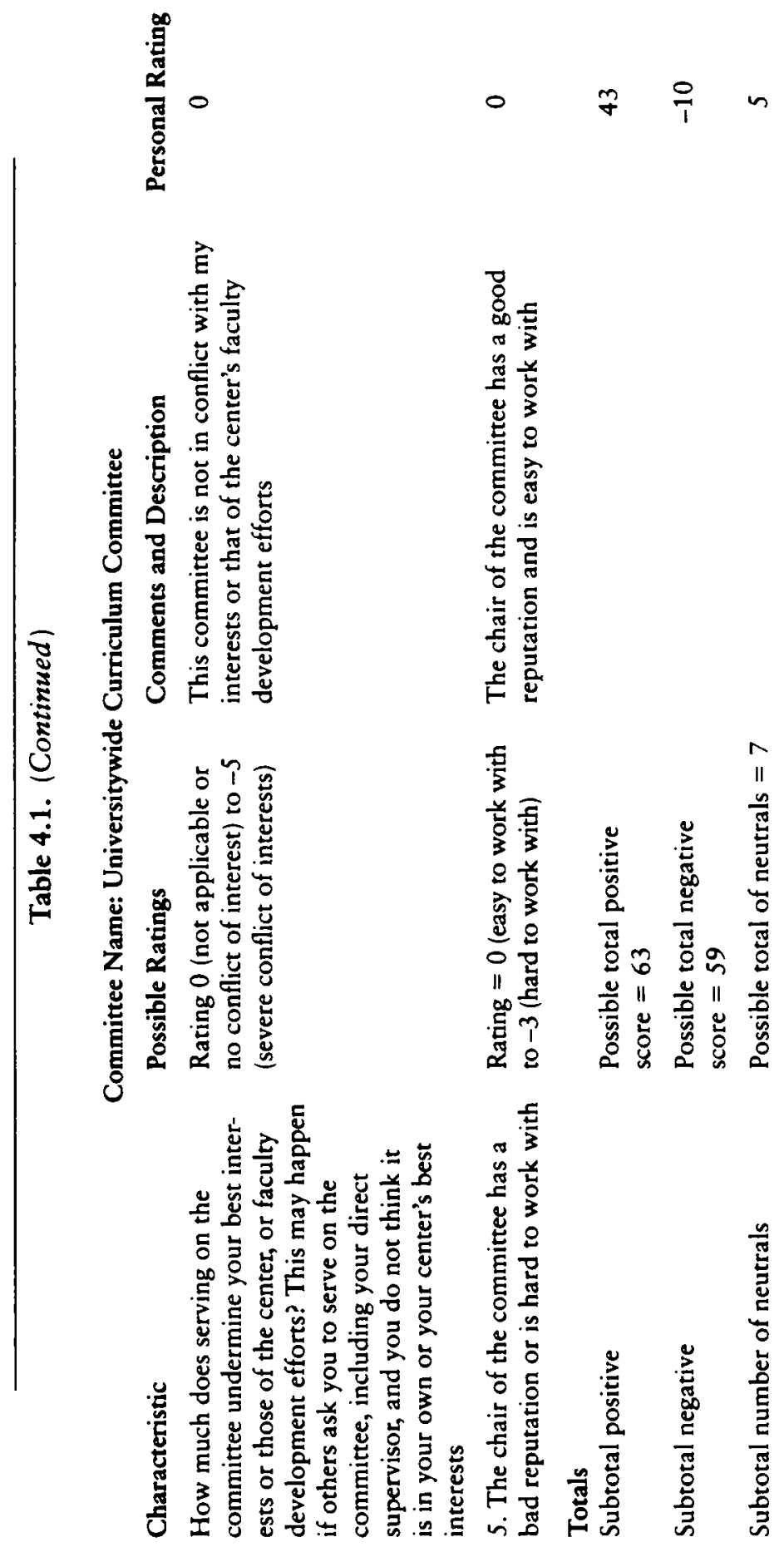



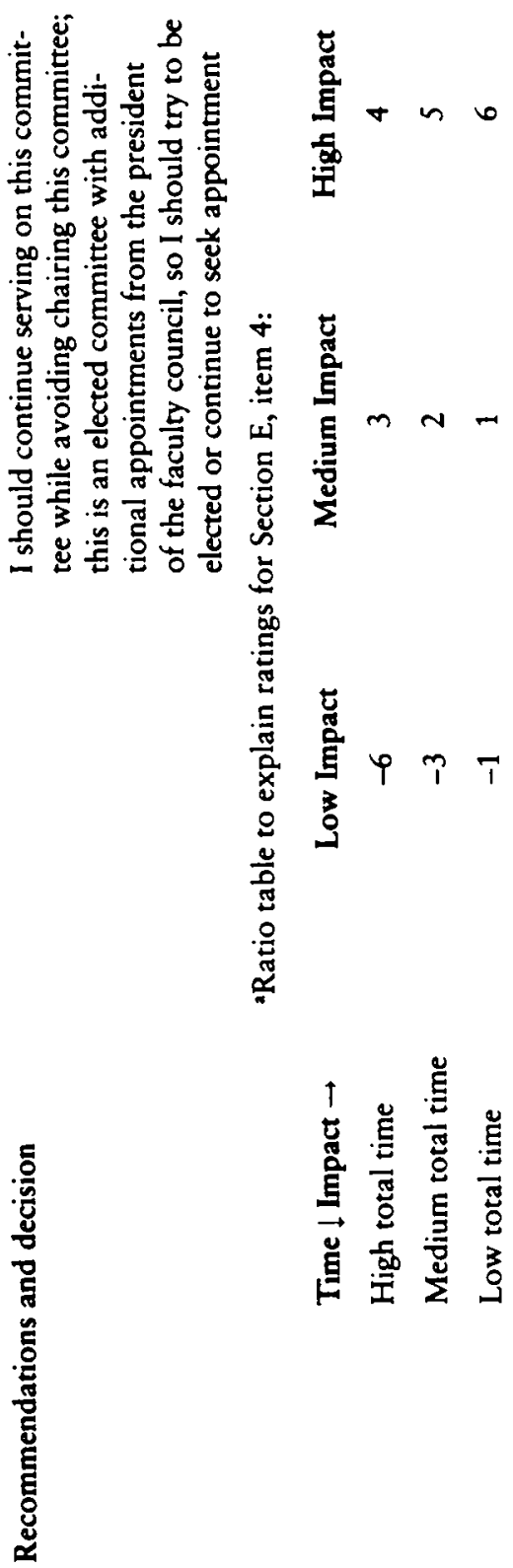


\section{REFERENCES}

Baron, L. (2006). The advantages of a reciprocal relationship between faculty development and organizational development in higher education. In S. Chadwick-Blossey \& D. R. Robertson (Eds.), To improve the academy: Vol. 24. Resources for faculty, instructional, and organizational development (pp. 29-43). Bolton, MA: Anker.

Beichner, R. J., \& Saul, J. M. (2003). Introduction to the SCALE-UP (student-centered activities for large enrollment undergraduate programs) project. Retrieved December 5, 2008, from www.ncsu.edu/PER/Articles/ Varenna_SCALE_Paper.pdf

Chism, N.V.N. (1998). The role of educational developers in institutional change: From the basement office to the front office. In M. Kaplan \& D. Lieberman (Eds.), To improve the academy: Vol. 17. Resources for faculty, instructional, and organizational development (pp. 141-153). Stillwater, OK: New Forums Press.

Diamond, R. M. (1995). Preparing for promotion and tenure review: A faculty guide. Bolton, MA: Anker.

Diamond, R. M. (2002). Faculty, instructional, and organizational development: Options and choices. In K. H. Gillespie, L. R. Hilsen, \& E. C. Wadsworth (Eds.), A guide to faculty development: Practical advice, examples, and resources (pp. 2-8). Bolton, MA: Anker.

Gillespie, K. H. (in press). Administrative and organizational development. In K. H. Gillespie \& D. R. Robertson (Eds.), A guide to faculty development: Practical advice, examples, and resources (2nd ed.). San Francisco: Jossey-Bass.

Gillespie, K. H., Hilsen, L. R., \& Wadsworth, E. C. (Eds.). (2002). A guide to faculty development: Practical advice, examples, and resources. Bolton, MA: Anker.

Gillespie, K. H., \& Zinsmeister, D. (2004, November). Exploring organizational development: Getting involved in decision-making. Paper presented at the 29th annual meeting of the Professional and Organizational Development Network in Higher Education, Montreal.

Lieberman, D. A., \& Guskin, A. F. (2003). The essential role of faculty development in new higher education models. In C. M. Wehlburg \& S. ChadwickBlossey (Eds.), To improve the academy: Vol. 21. Resources for faculty, instructional, and organizational development (pp. 257-272). Bolton, MA: Anker.

Marshall, W. J. (1999). University service. In V. Bianco-Mathis \& N. Chalofsky (Eds.), The full-time faculty handbook (pp. 113-128). Thousand Oaks, CA: Sage. 
Schroeder, C. (2006, October). Coming in from the margins: Redefining faculty development's institutional role. Paper presented at the 31 st annual meeting of the Professional and Organizational Development Network in Higher Education, Portland, OR.

Schroeder, C. (in press). Coming in from the margins: Redefining faculty development's institutional role. Sterling, VA: Stylus. 